\title{
4 \\ Interpretação dos gestores da região de Campinas sobre a Alimentação Escolar
}

\author{
Rosana Maria Nogueira¹, Betzabeth Slater Villar², Bruna Barone³, Kátia Regina Leoni \\ Silva Lima de Queiroz Guimarães ${ }^{3}$ e Jorge Herman Behrens ${ }^{3}$
}

O Programa Nacional de Alimentação Escolar (PNAE) é uma política pública de atendimento universal aos alunos das escolas públicas brasileiras e tem suas rotinas e procedimentos bem definidos. A Lei Federal no 11.947 de 2009 foi um grande avanço após décadas de ações e investimentos públicos, assim este estudo objetivou revelar, analisar e compreender os conhecimentos, interpretações, e práticas dos Secretários Municipais da Educação e Nutricionistas - Responsáveis Técnicos; os gestores dos programas municipais de alimentação escolar da Região Metropolitana de Campinas (RMC), em relação à legislação que o define. $\mathrm{O}$ estudo teve abordagem qualitativa realizada por meio de entrevistas com os gestores do PNAE nos municípios da RMC em 2014 e 2015. Para a análise do conteúdo das entrevistas foi utilizada a técnica do Discurso do Sujeito Coletivo (DSC), baseada na Teoria das Representações Sociais. O discurso dos secretários de educação revelou seu papel político, muitas vezes demonstrando desconhecimento sobre a dimensão e sobre a legislação de referência do programa de alimentação escolar. O discurso dos nutricionistas demonstrou dificuldade em seguir a legislação de referência do PNAE por questões técnicas ou falta de preparo. De forma geral, os discursos dos gestores revelaram uma interpretação assistencialista da alimentação escolar, diferentemente do que propõe o PNAE. A representação social de alimentação escolar entre os gestores é a denominação "merenda", embora reconheçam que este conceito seja ultrapassado. Observa-se a necessidade de atualização dos gestores públicos e melhor capacitação, assim como a inclusão de disciplinas voltadas à área de gestão de políticas públicas no currículo dos cursos de nutrição.

Palavras-chave: Alimentação escolar, Políticas públicas, Nutrição.

\section{Interpretation of Campinas region managers about School Feeding}

The National School Feeding Program (PNAE), with its well-defined routines and procedures, is a public policy of universal service to the students of Brazilian public schools. Federal Law n. 11.947/2009 was a considerable step forward, the culmination of decades of initiatives and public investment. This study serves to interpret the

\footnotetext{
1 Pós-doutoranda do Departamento de Nutrição, Faculdade de Saúde Pública, Universidade de São Paulo, Brasil. Faculdade de Saúde Pública - USP. Endereço para correspondência: Av. Dr. Arnaldo no 715, São Paulo, Brasil. CEP: 01246-904. Telefone: (19)99111-5640. E-mail: rosamanogueira@yahoo.com.br

2 Departamento de Nutrição, Faculdade de Saúde Pública, Universidade de São Paulo, Brasil.

${ }^{3}$ Departamento de Alimentos e Nutrição, Faculdade de Engenharia de Alimentos, Universidade Estadual de Campinas, Brasil.
} 
knowledge and practices of the Municipal Secretaries of Education and Nutritionists - the managers responsible for the municipal school feeding programs of the Metropolitan Region of Campinas (RMC). This study, conducted through a series of interviews with PNAE managers from the municipalities of the RMC from 2014 to 2015, takes a qualitative approach. The Collective Subject Discourse (DSC) technique, with its roots in the Theory of Social Representations, was used in the analysis of these interviews. The discourse of the Secretaries of Education reflected their political role, often proving ignorant of the scale and legislation of the PNAE. The nutritionists seemed to find following the PNAE reference legislation difficult as a result of technical difficulties or a general lack of preparation. Broadly speaking, the managers appeared to possess an assistentialist interpretation of school feeding, contrary to what is proposed by the PNAE. The social representation of school feeding amongst the managers is referred to as 'merenda', although they recognize that this concept is outdated. It is clear that public managers must be brought up to speed and that better training must be made available. Furthermore, the curriculum of nutrition courses must be improved, so as to better develop the disciplines necessary for the satisfactory management of public policy.

Keywords: School feeding, Public policy, Nutrition.

\section{INTRODUÇÃO E OBJETIVOS}

O Programa Nacional de Alimentação Escolar é o segundo maior do mundo, atendendo diariamente 50 milhões de alunos, estando à sua frente apenas o programa de alimentação escolar da Índia, que oferece refeições a mais de 100 milhões de alunos $\left[{ }^{[1]}\right.$.

A universalidade, assim como a continuidade, são princípios que sempre guiaram o programa brasileiro. Porém, na sua execução, há dificuldade em alcançá-los, seja por pressões externas à gestão do programa, por pressões políticas, por pressões acadêmicas ou até mesmo por pressões pessoais ao longo de sua história [2].

O PNAE é ininterrupto e instituiu-se como direito básico, com a garantia do fornecimento de refeições em 200 dias letivos ao ano, a todos os alunos matriculados na educação básica das redes públicas federal, estadual, distrital e municipal; nas creches, préescolas, ensino fundamental, ensino médio, e educação de jovens e adultos, bem como para os matriculados nas entidades filantrópicas, confessionais e comunitárias. Este atendimento foi ampliado para o ensino médio e educação de jovens e adultos a partir de junho de 2009[3].

Tem como objetivo primordial contribuir para o crescimento biopsicossocial, aprendizagem, rendimento escolar e formação de práticas alimentares saudáveis dos alunos por meio de educação alimentar e nutricional e, da oferta de refeições que atendam às necessidades nutricionais durante o período letivo ${ }^{[3]}$. Tornou-se uma estratégia importante para a segurança alimentar e nutricional quando passou a promover o Direito Humano à Alimentação Adequada (DHAA) ${ }^{[4]}$.

A coordenação das ações de alimentação e nutrição no nível da entidade executora (distrito federal, estados e municípios) é realizada por um nutricionista que assume a responsabilidade técnica. Aos secretários municipais e/ou estaduais de educação cabe a operacionalização administrativa e financeira do PNAE e, ainda, a instituição do controle social por meio dos Conselhos de Alimentação Escolar (CAE)[2]. Ações estas pautadas na Lei Federal no 11.947 de 16 de junho de 2009 e na Resolução/CD/FNDE no 26 de 17 de junho de 2013[3,5].

Para a operacionalização do PNAE é prevista a transferência de recursos financeiros federais para entidades executoras sem necessidade de convênio, ajuste, acordo ou contrato com o objetivo exclusivo de adquirir gêneros alimentícios com o devido planejamento e controle de qualidade. O repasse é feito em dez parcelas mensais, correspondentes a vinte dias letivos por mês, que em 2015 totalizou $\mathrm{R} \$ 3,7$ bilhões de reais, apresentados nos seus respectivos valores per capita na Tabela ${ }^{[6] .}$ 
Tabela 1. Recursos financeiros federais transferidos às entidades executoras para a operacionalização do PNAE a partir da Resolução/CD/FNDE no 01, de 08 de fevereiro de 2017

\begin{tabular}{|c|c|}
\hline Modalidades de Ensino & $\begin{array}{l}\text { Valores transferidos } \\
(\mathbf{R} \$)\end{array}$ \\
\hline Ensino Fundamental, Ensino Médio & 0,36 \\
\hline Educação de Jovens e Adultos - EJA & 0,32 \\
\hline $\begin{array}{l}\text { Pré-Escola (exceto para aqueles matriculados em escolas localizadas em áreas indígenas e } \\
\text { remanescentes de quilombos) }\end{array}$ & 0,53 \\
\hline Escolas de Educação Básica (localizadas em áreas indígenas e remanescentes de quilombos) & 0,64 \\
\hline $\begin{array}{l}\text { Escolas de tempo integral (com permanência mínima de sete horas) na escola ou em } \\
\text { atividades escolares) }\end{array}$ & 1,07 \\
\hline Creches (inclusive as localizadas em áreas indígenas e remanescentes de quilombos) & 1,07 \\
\hline Programa de Fomento às Escolas de Ensino Médio em Tempo Integral & 2,00 \\
\hline Atendimento Educacional Especializado - AEE & 0,53 \\
\hline
\end{tabular}

Os recursos financeiros federais destinados a este programa podem ainda ser transferidos diretamente às escolas, porém a Entidade Executora (município ou estado) é a responsável por receber o recurso e repassar à escola. A prestação de contas ao CAE e posteriormente ao próprio FNDE sobre os recursos recebidos e destinados à operacionalização do PNAE, cabe à entidade executora.

Deve haver a complementação do recurso financeiro federal com recursos estaduais e municipais e a partir desta disponibilidade financeira ocorrer então a oferta da alimentação nas escolas, prevista na seção II artigo 14 da Resolução/CD/FNDE no 26/2013, sendo os cardápios elaborados por nutricionista, responsável técnico pelo programa. Estes cardápios devem conter "gêneros alimentícios básicos, respeitar as preferências nutricionais, os hábitos alimentares, a cultura alimentar da localidade e pautar-se na sustentabilidade, sazonalidade e diversificação agrícola da região e na alimentação saudável e adequada"[5].

Para a fiscalização de toda a operacionalização do PNAE, o programa conta com a participação efetiva do CAE que é um órgão colegiado permanente, deliberativo e de assessoramento. A fiscalização do uso dos recursos financeiros do programa cabe ao Tribunal de Contas da União (TCU) e outros órgãos de controle interno do Governo Federal[ $[$ ]. Os demais aspectos relacionados à eficiência do programa, como os técnico-administrativos, não são avaliados, embora tal avaliação seja preconizada pela ONU[8].

\section{Abordagem Qualitativa em Pesquisa Social}

Uma forma de pesquisar o comportamento do indivíduo se faz por meio de entrevistas focadas em atitudes (componente afetivo), conhecimento (componente cognitivo) e comportamento (componente conativo) de forma a revelar ideias, sentimentos, valores e práticas que permitam entender o processo de realização do indivíduo ou mesmo identificar padrões de comportamento comuns a um grupo de indivíduos ${ }^{[9,10,11]}$.

A pesquisa qualitativa torna-se uma reflexão do pesquisador e é orientada para análise de casos concretos em sua particularidade temporal e local, partindo das expressões e atividades das pessoas em 
seus contextos locais $\left[{ }^{[]}\right.$. Estas características justificam a escolha da metodologia para a pesquisa com gestores do PNAE nos municípios da RMC.

Entretanto, é necessário um referencial teórico para análise do conteúdo de entrevistas para melhor organizar e interpretar os dados obtidos. Neste sentido, a Teoria das Representações Sociais tem um grande potencial de aplicação em pesquisa qualitativa.

\section{Teoria das Representações Sociais - TRS}

\section{Representações Sociais referem-se ao} conjunto de explicações, crenças e ideias que permitem evocar um dado acontecimento, pessoa ou objeto. São resultantes da interação social, pelo que são comuns a um determinado grupo de indivíduos.

$\mathrm{Na}$ conceituação de Serge Moscovici (psicólogo social que teorizou as representações sociais, em 1961), entende-se por representações sociais um conjunto de conceitos, proposições e explicações originado na vida cotidiana, no desenrolar das comunicações interpessoais ${ }^{[12] .}$

Os dados de uma pesquisa qualitativa podem ser interpretados com maior objetividade $\mathrm{e}$ confiabilidade quando as pesquisas fundamentadas na Teoria das Representações Sociais utilizarem o Discurso do Sujeito Coletivo como método sistemático de análise dos dados ${ }^{[13]}$, que consiste num conjunto de instrumentos destinados a recuperar e dar à luz as representações sociais, principalmente as que aparecem sob a forma verbal[10,11].

\section{Discurso do Sujeito Coletivo - DSC}

É um método sistemático de análise dos dados desenvolvido na Universidade de São Paulo na década de 1990. Este método considera que a forma de pensar e de agir dos indivíduos é determinada pela sua esfera social e pelos significados nela compartilhados, ou seja, pelas representações sociais ${ }^{[11,14]}$.

O DSC utiliza estratégias para descrever o sentido dos discursos por meio de figuras metodológicas tais como, expressões-chave, ideias centrais (objetivações) e as ancoragens ${ }^{[10]}$. A elaboração final do DSC é a reunião das expressões-chave que apresentam ideias centrais ou ancoragens semelhantes redigido na primeira pessoa do singular. É todo o material produzido a partir do trabalho de campo, as entrevistas, os questionários ${ }^{[11,15]}$.

Assim, na medida em que os discursos são construídos, compõe-se a interpretação dos participantes, as relações estabelecidas por eles no contexto social, seus comportamentos e suas práticas. O DSC resgata as representações sociais e reconstrói o pensamento coletivo, possibilitando o compartilhamento de ideias dentro de um grupo social[11].

\section{Região Metropolitana de Campinas - RMC}

A Região Metropolitana de Campinas foi criada pela Lei Complementar Estadual no 870/2000[16] e é uma das regiões mais dinâmicas no cenário econômico brasileiro, formada por municípios com diversidade entre os seus aspectos populacionais, mas com índices de desenvolvimento similares ${ }^{[17]}$.

É composta por vinte municípios: Americana, Artur Nogueira, Campinas, Cosmópolis, Engenheiro Coelho, Holambra, Hortolândia, Indaiatuba, Itatiba, Jaguariúna, Morungaba, Monte Mor, Nova Odessa, Paulínia, Pedreira, Santa Bárbara d'Oeste, Santo Antônio de Posse, Sumaré, Valinhos, Vinhedo, sendo que Morungaba foi integrada à RMC em março de 2014, pela Lei Estadual no 1.234[18]. Estes municípios ocupam uma área de $3.800 \mathrm{~km}^{2}$, com uma população de aproximadamente 3 milhões de habitantes. Campinas abriga $38 \%$ da população metropolitana e os municípios de Americana, Hortolândia, Indaiatuba e Santa Bárbara d'Oeste têm cada um, mais de 200 mil habitantes ${ }^{[17]}$.

O Índice de Desenvolvimento Humano (IDH) da Região Metropolitana de Campinas é 0,792, o melhor entre as regiões metropolitanas do Brasil, segundo dados do PNUD[19].

Em relação à educação a RMC é uma das regiões do Brasil com melhores indicadores, contando com mais de mil escolas de educação infantil, ensino fundamental e médio atendidas pelo PNAE. São escolas das redes pública (estadual e municipal), com aproximadamente 590 mil alunos ${ }^{[20] .}$ 
Considerando essas características de excelência da RMC, como a economia sólida, infraestrutura que favorece o desenvolvimento metropolitano, a estratégica possibilidade de logística, e ainda, o acesso privilegiado à informação, foi tomada a decisão de diagnosticar o que os gestores públicos conhecem sobre a legislação do PNAE para poder implementá-lo adequadamente, fazendo com que o direito do aluno na escola pública à alimentação saudável e adequada seja preservado e o ciclo do desenvolvimento humano não cesse.

\section{OBJETIVO GERAL}

Levantar e analisar a formação, os conhecimentos, interpretações e opiniões e conhecer práticas dos Secretários Municipais da Educação e Nutricionistas - Responsáveis Técnicos, ou seja, os gestores dos programas municipais de alimentação escolar da RMC, em relação à Lei Federal no 11.947/2009 e à Resolução/CD/FNDE no 26/2013 que definem o Programa Nacional de Alimentação Escolar (PNAE).

\section{MATERIAL E MÉTODOS}

A pesquisa de campo foi realizada nos anos de 2014 e 2015, com gestores do PNAE; secretários de educação e nutricionistas dos municípios da RMC, com o objetivo de revelar seu entendimento sobre a legislação de referência do PNAE, bem como crenças, opiniões, práticas e percepções gerais sobre os programas municipais de alimentação escolar. Trata-se de um estudo observacional com abordagem qualitativa. A abordagem quantitativa foi utilizada especificamente para descrição de aspectos da gestão do PNAE.

Os gestores de cada município da RMC assinaram a autorização de coleta de dados com esclarecimentos sobre os objetivos, justificativa e metodologia da pesquisa, assim como o Termo de Consentimento Livre Esclarecido (TCLE), que além dos esclarecimentos sobre os objetivos da pesquisa, também versou sobre o sigilo e a guarda das informações. O termo esclareceu, ainda, que os resultados seriam codificados $\mathrm{e}$ as informações utilizadas apenas para alcançar o objetivo da pesquisa e compor o relatório final.
O protocolo de pesquisa registrado na Plataforma Brasil do Ministério da Saúde, seguindo a Resolução CNS no 466/2012, teve a aprovação do Comitê de Ética em Pesquisa (CEP) da Universidade Estadual de Campinas (Unicamp), por meio do Certificado de Apresentação de Apreciação Ética (CAAE) de número 15720813.3.0000.5404.

\section{Sujeitos da Pesquisa}

Os sujeitos que compuseram o universo do estudo foram os secretários de educação como responsáveis administrativos e os nutricionistas como responsáveis técnicos pela alimentação escolar dos vinte municípios da RMC.

O Sistema de Cadastro de Nutricionistas do PNAE (SINUTRI), baseado no site do Fundo Nacional de Desenvolvimento da Educação (FNDE) na internet, foi utilizado no levantamento dos responsáveis técnicos da alimentação escolar dos municípios da RMC[6]. Nos sites oficiais das prefeituras da RMC foram identificados os secretários municipais de educação. Foram encaminhados convites para a participação na pesquisa e mediante a anuência dos secretários municipais de educação, agendadas as entrevistas. O TCLE informou que as entrevistas seriam gravadas em áudios e os mesmos seriam mantidos durante o período da pesquisa, sendo posteriormente extintos.

\section{Guias de Entrevistas}

Um guia de entrevistas semiestruturado foi elaborado para os dois grupos de sujeitos contendo perguntas abertas sobre o tema da pesquisa com a intenção de estimular respostas discursivas ${ }^{[14,21]}$.

Basicamente, o guia abordou o conhecimento sobre o programa de alimentação escolar, a legislação pertinente, a importância e a aplicabilidade da legislação na implementação do programa no município.

As questões do guia foram elaboradas de forma a contemplar componentes cognitivos (crenças e conhecimento que o sujeito possui referente a um dado objeto), conativos (tendências de comportamentos da pessoa quanto ao objeto 
estudado) e afetivos (congrega os sentimentos a favor ou contra o objeto) [22].

Nas entrevistas também foram abordadas particularidades administrativas, com o objetivo de verificar o quanto o secretário e o RT se inteiravam da gestão da alimentação escolar no município.

Antecedendo o início do trabalho de campo, os guias de entrevistas foram testados com especialistas em alimentação escolar, acadêmicos e com secretários municipais de educação e nutricionistas de três municípios não participantes da pesquisa.

As entrevistas foram conduzidas individualmente e os áudios obtidos foram transcritos por profissional especializado para que se procedesse à análise do conteúdo verbal.

\section{Análise do Conteúdo}

Após a transcrição das entrevistas foi realizada a análise pelo pesquisador principal e dois colaboradores do grupo de pesquisa, com o objetivo de minimizar possíveis vieses de interpretação[?]. A análise do conteúdo das entrevistas seguiu o método do DSC, proposto por Lefèvre e Lefèvre ${ }^{[10]}$, e compreendeu os seguintes passos:

I - Identificação das expressões-chave (ECH): destaques dos trechos do discurso que realmente responderam às perguntas;

II - Identificação das ideias centrais (IC): nomes ou expressões linguísticas que descreveram de forma breve e precisa o significado das expressões-chave;

III - Identificação das ancoragens (AC): trechos dos discursos que demonstram como o conhecimento acerca do objeto estudado se insere no cotidiano do sujeito.

Os três pesquisadores analisaram individualmente as entrevistas, selecionando as figuras metodológicas que posteriormente foram definidas, consensualmente, em cada entrevista. As expressõeschave foram agrupadas em categorias analíticas determinadas pela semelhança de ideias centrais nelas contidas, compiladas para a redação do discurso síntese na primeira pessoa do singular, representando a "voz" dos secretários municipais de educação e nutricionistas sobre o PNAE.

Complementando a análise foram utilizados os atributos quantitativos do DSC que são a intensidade/força e amplitude. A intensidade refere-se ao número ou percentual de entrevistados que contribuíram com suas expressões-chave relativas às ideias centrais ou ancoragens semelhantes ou complementares, para a elaboração de um DSC. Assim, foi possível identificar o grau de compartilhamento das Representações Sociais entre a população pesquisada. A amplitude, por sua vez, refere-se à presença de uma ideia ou representação social considerando o campo ou universo pesquisado, revelando ao pesquisador o grau de difusão de uma ideia entre os sujeitos ${ }^{[10]}$.

O software Qualiquantisoft $₫$ foi utilizado para cadastrar os entrevistados, as ideias centrais e expressões-chave associadas e redação do DSC[23].

\section{RESULTADOS E DISCUSSÃO}

\section{Gestão dos Programas Municipais de Alimentação Escolar}

Para as entrevistas acontecerem, foram necessários vários contatos com os municípios, por problemas políticos, mudanças de secretários municipais de educação no período da pesquisa e desconfiança dos nutricionistas em relação ao estudo. Foi possível contatar 17 (85\%) secretários e 19 (95\%) nutricionistas, dos 20 municípios que compõem a RMC. Três secretários $(15 \%)$ e um nutricionista (5\%) recusaram a participação neste estudo.

Dos 17 secretários entrevistados, todos têm formação acadêmica em nível superior, em áreas da educação. Dos 20 municípios, 17 (85\%) têm estrutura administrativa de secretaria de educação, e três $(15 \%)$, de diretoria, sendo que todos respondem política e administrativamente ao prefeito, diretamente.

As questões sobre a administração do programa municipal de alimentação escolar, como o modelo de gestão, a rede de escolas e o número de escolas por modalidade de ensino, o número de alunos atendidos e a logística tiveram o objetivo de 
comparação do conhecimento entre gestores (secretários e nutricionistas).

Os gestores denominam o setor responsável pela alimentação escolar de várias formas: "merenda escolar", somente "merenda", "alimentação escolar", "nutrição", mas em todos os municípios essa área de gestão é vinculada diretamente ao secretário/diretor de educação. E esta vinculação pode se dar por meio de um funcionário que não é o nutricionista, o que ocorre em 11 municípios (55\%) da região. A vinculação da área de gestão do programa de alimentação escolar diretamente com o nutricionista é a estrutura de outros oito municípios (40\%). Não foi possível conhecer a estrutura de um município (5\%), que recusou a entrevista.

O programa de alimentação escolar na RMC atende à Lei Federal no 11.947/2009, artigo 11, quanto à responsabilidade técnica, pois todos os munícipios têm um nutricionista responsável no seu quadro de funcionários[3]. Em contrapartida, com relação à legislação do Conselho Federal de Nutricionistas, que estabelece parâmetros numéricos mínimos de referência para responsável e quadro técnico por entidade executora, para educação básica, Resolução CFN no 465/2010[24], nenhum dos municípios atende, pois se constatou que em 12 municípios (60\%) o programa de alimentação escolar conta somente com um nutricionista que é responsável técnico para a implementação de todo o programa, sem dispor do quadro técnico proposto. Em quatro deles (20\%), atuam o RT e mais um nutricionista. Atuam o RT e mais dois nutricionistas em dois municípios (10\%) e em apenas um (5\%) atuam o R'T e mais 3 nutricionistas. Um município $(5 \%)$ não respondeu à pesquisa. Vale ressaltar que para o município contar com apenas um nutricionista como Responsável Técnico, de acordo com a legislação, deveria oferecer até quinhentas refeições, o que não acontece em nenhum dos municípios da RMC. Somente um município conta com o menor número de refeições, 2600 .

Scarparo et al.[25] referem no estudo realizado em municípios do Rio Grande do Sul que o nutricionista desempenha a função de forma isolada, sem pares na profissão para discutir, dirimir dúvidas e solucionar conflitos, o que confirma o achado na maioria dos municípios da RMC.
Quanto ao modelo de gestão implementado pelos municípios para o programa de alimentação escolar, a autogestão é predominante na RMC. Este modelo preconiza que a implementação do programa de alimentação escolar esteja totalmente a cargo do município e seja realizada pela área competente da secretaria/diretoria de educação. Os municípios que adotam esse modelo na RMC são 15 (75\%), sendo que um deles compartilha a gestão com outro órgão público, uma central de abastecimento - sociedade de economia mista e outro contrata de terceiros a mão de obra de cozinheiras.

A terceirização do programa de alimentação escolar, que é a transferência das atividades de operacionalização do programa por meio de licitação pública para empresas privadas, é a opção de modelo de gestão de cinco municípios (25\%) da RMC, sendo que um deles terceiriza o programa utilizando uma cozinha central (piloto) para preparar apenas as refeições quentes. As demais preparações (saladas, sobremesas e sucos) são feitas nas cozinhas das escolas, sendo parte da mão de obra também terceirizada. Este é um exemplo de difícil gestão, pois reúne várias modalidades em um único município além de sobrepor a estrutura de cozinha, pois existem a cozinha central e as das escolas, desempenhando as mesmas funções.

Comparando as respostas dos gestores sobre qual o modelo de gestão do PNAE implementado no município - autogestão ou terceirização - 14 (70\%) deles responderam igualmente, isto é, o secretário e o nutricionista deram a mesma resposta sobre o modelo de gestão do programa. Em $2(10 \%)$ municípios os gestores responderam de forma diferente sobre $\mathrm{O}$ mesmo modelo. Não souberam a informação completa, em outras palavras, responderam de forma equivocada. Em outros 2 (10\%) municípios somente os nutricionistas responderam. E em 1 (5\%) município as respostas foram diferentes entre o secretário e o nutricionista, um gestor respondeu que era autogestão e o outro que o modelo era descentralizado. Em um (5\%) município nem o secretário nem o nutricionista respondeu sobre o modelo de gestão implementado.

Isto demonstra consonância, conhecimento e segurança do modelo de gestão implementado na maioria dos municípios, por ambos gestores. Porém nos demais municípios os resultados denotam certa fragilidade da gestão ou mesmo despreparo para o 
desempenho das funções, devida à discrepância entre as respostas dos gestores no conhecimento sobre como se implementa o programa no município sob sua responsabilidade.

Quanto às modalidades de ensino (creche, educação infantil - pré-escola, ensino fundamental, ensino integral, ensino médio, educação de jovens e adultos) oferecidas no município, todos os 17 secretários entrevistados responderam demonstrando conhecer as modalidades que atendem. Porém, quanto ao número de escolas existentes, 11 (65\%) secretários responderam adequadamente, demonstrando conhecer a realidade; $5(29 \%)$ não responderam, pois precisariam "checar os dados"; e um $(5 \%)$ respondeu de maneira incompleta, pois não sabia exatamente o número das escolas existentes no seu município.

Com relação ao número de alunos atendidos em cada modalidade, $8(47 \%)$ secretários responderam adequadamente, conhecendo a sua demanda; 6 (35\%) não responderam pois não sabiam o número exato e 3 $(18 \%)$ responderam de maneira incompleta, pois precisariam "checar as informações". E quanto à delegação de rede, isto é, a transferência da responsabilidade do Estado ao município em relação à oferta de alimentação para os alunos das escolas estaduais, localizadas em cada município optante desta modalidade, $15(88 \%)$ secretários disseram que sim, atendem às escolas estaduais e dois $(12 \%)$ não tinham certeza. Estes achados refletem desconhecimento de informação fundamental para a gestão da educação no município. $\mathrm{O}$ número de alunos havia sido previamente pesquisado no site do Observatório Metropolitano Indicadores da RMC - Agência Metropolitana de Campinas.

Quando os nutricionistas foram questionados sobre as modalidades de ensino, dos 19 entrevistados $18(95 \%)$ responderam adequadamente e um $(5 \%)$ respondeu de maneira incompleta, pois não tinha certeza quanto às modalidades atendidas. Quanto ao número de escolas atendidas em cada modalidade de ensino, $10(53 \%)$ nutricionistas sabiam o número exato e citaram cada uma delas, 7 (37\%) não souberam responder, solicitando enviar os dados posteriormente e $2(10 \%)$ responderam de maneira incompleta, pois tinham dúvidas. Para a informação sobre o número de alunos atendidos em cada escola, 10 (53\%) nutricionistas pediram para enviar os dados posteriormente, pois não sabiam responder no momento da entrevista, $8(42 \%)$ souberam responder adequadamente e um $(5 \%)$ respondeu de maneira incompleta, pois tinha dúvidas.

Quanto à delegação de rede, 17 nutricionistas $(89 \%)$ responderam positivamente, que havia a delegação de rede para o programa de alimentação escolar e dois $(11 \%)$ ficaram em dúvida se havia ou não delegação de rede no município.

A intenção desse questionamento foi verificar se os secretários, assim como os nutricionistas, conheciam exatamente o seu objeto de trabalho. Porém, o que foi demonstrado nas respostas, principalmente dos nutricionistas, é que aspectos básicos para a gestão do programa de alimentação escolar como números de escolas e alunos não são informações precisas para quem deve assumir a responsabilidade técnica atendendo o item II do artigo 12, inciso 1o da Resolução/CD/FNDE no 26/2013 que é "planejar, elaborar, acompanhar e avaliar o cardápio da alimentação escolar de acordo com a cultura alimentar, o perfil epidemiológico da população atendida e a vocação agrícola da região, acompanhando desde a aquisição dos gêneros alimentícios, o preparo, a distribuição até o consumo das refeições pelos escolares"[[].

A partir das entrevistas realizadas com os secretários e nutricionistas foram gerados os DSC juntamente com as ideias centrais e a intensidade/força (frequência de indivíduos que contribuíram com as expressões-chave) de cada ideia central.

\section{Significado da Alimentação Escolar}

Os secretários de educação da RMC foram questionados sobre "O que significa a Alimentação Escolar?" e no seu discurso verificaram-se ideias centrais, como "Alimentação adequada", "Outro momento da Educação" e "Assistencialismo".

Pode-se notar sobre esse questionamento que nenhum discurso contempla a alimentação escolar como uma política pública formulada e implementada no âmbito da educação. 
Quando se referiram a uma "Alimentação adequada", nota-se um viés assistencialista nesta representação...

"... g gente trabalha com os alunos que não
tem alimentacão saudável em casa".

Camozzi et al.[26] destacaram a alimentação na escola como estímulo a autonomia, ao exercício dos direitos e deveres, ao controle das condições de saúde e qualidade de vida. Destacaram, ainda, que a alimentação adequada e saudável foi vista no espaço da escola como garantia da segurança alimentar e nutricional, na medida em que complementa a alimentação do aluno de forma qualitativa. Entretanto, verificaram que existia a percepção da alimentação escolar como artifício para evitar a evasão escolar, principalmente dos alunos carentes.

Freitas et al.[27] relataram em seu estudo que há lugares que a alimentação escolar se institui como o melhor momento das crianças na escola, com preparações variadas e comensalidade, atendendo principalmente, o estudante desnutrido pois, ao reduzir a privação de alimentos vivida, a escola inscreve nesses jovens um valor social articulado.

$\mathrm{Na}$ ideia central "Outro momento da educação", embora o conceito da alimentação escolar tenha se ampliado como mais uma atividade pedagógica que acontece no ambiente da escola, a concepção assistencialista permeia o discurso quando entendem que...

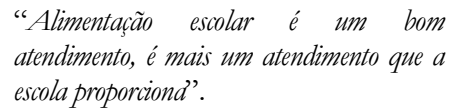

Carvalho ${ }^{[28]}$ discutiu que a prática assistencialista do programa de alimentação escolar foi paulatinamente substituída ao longo da sua história pela prática promotora da saúde, dinamização da economia, inclusão social, respeito à cultura e hábitos alimentares. Porém, no discurso dos secretários municipais de educação da RMC, estas ideias ainda aparecem secundárias frente à assistência da necessidade básica da alimentação do estudante.

"Muitos casos que eles vêm mais para alimentar do que para aprender... pra nós é sério porque não são todos, mas a gente sabe que para várias familias, às vezes, é a única alimentação que a criança tem, principalmente as menos favorecidas...pra mim significa um reforço do estímulo de ir à escola. Hoje muitas crianças vão à escola por conta da alimentação".

Embora haja uma percepção de alimentação escolar como: "Outro momento da educação", Bezerraa ${ }^{[29]}$ em sua pesquisa constatou que o plano do trabalho escolar ainda se organiza em função da existência ou não da oferta da alimentação. Quando há "merenda", os alunos permanecem na escola cerca de quatro horas e quando não há, o tempo de trabalho destinado às atividades curriculares é subtraído e muitas vezes suprime-se o recreio para ganhar mais tempo e liberar os alunos mais cedo.

No contexto da legislação atual pode-se entender que o estímulo à permanência do aluno na escola, bem como a diminuição da evasão e da repetência devem ser objetivos do projeto pedagógico da escola. Mas nem sempre foi assim, pois na Resolução/CD/FNDE no 7/2000 foi descrito entre os objetivos do programa no artigo 2o, "O PNAE consiste na transferência de recursos financeiros em favor das Entidades Executoras..., destinados a suprir parcialmente as necessidades nutricionais dos alunos, com vistas a melhorar o rendimento escolar, colaborando para a redução da evasão e repetência, assim como formar bons hábitos alimentares"[30].

Rodrigues $^{[31]}$ relatou em seu estudo, que ainda na década de 1980, os gestores tentavam definir o papel a ser cumprido pela escola na solução dos problemas relacionados à desnutrição, educação e pobreza, diante da afirmação de que as escolas estavam se tornando "grandes restaurantes" e, por consequência, sendo assistencialistas.

Neste sentido, o discurso dos secretários de educação reflete ideias do passado e reforça a permanência da concepção assistencialista e equivocada em relação ao objetivo do programa e da escola que secretários e nutricionistas da RMC ainda têm. Assim, o PNAE ainda é percebido como uma política assistencialista e não de direito do aluno, como preconiza a legislação de referência do PNAE[3].

Há, portanto, a necessidade de atividades educacionais que possibilitem o interesse do aluno pela escola e que durante sua permanência ele tenha o direito de receber a alimentação como parte das 
atividades lá desenvolvidas que compõem seu processo de aprendizagem.

Também se arguiu aos nutricionistas a mesma questão "O que significa a Alimentação Escolar para o(a) $\operatorname{Sr}(a)$ ?", verificando-se as ideias centrais "Alimentação saudável", "Suporte" e "Educação nutricional".

A ideia central "Alimentação saudável" revelada no discurso dos nutricionistas demonstrou uma percepção mais próxima ao que preconiza a legislação do PNAE[3]:

\footnotetext{
"Alimentação Escolar é completa, hoje. Acho que é você fornecer para o aluno, que permanece o periodo integral ou parcial na escola, uma alimentação saudável que atenda às necessidades nutricionais, para que consiga ter um aproveitamento intelectual suficiente, porque vem à escola para aprender e necessita de uma boa alimentacão, que siga ai as diretrizes do PNAE. É uma forma de garantir pelo menos uma refeição adequada para a crianca, para 0 adolescente, até mesmo para o adulto no dia, oferecendo nutrientes e alimentos, é algo assim, não é assistencialista. Então a gente tem que prestar muita atenção no que a gente fornece, na qualidade".
}

Este discurso demonstrou a percepção técnica da alimentação escolar, a necessidade de exercer as atividades segundo as determinações da Resolução CFN 465/2010[24], como o diagnóstico e o acompanhamento do estado nutricional dos escolares, identificação de indivíduos com necessidades nutricionais específicas, planejamento, elaboração, acompanhamento e avaliação do cardápio da alimentação escolar ${ }^{[32] .}$

A ideia central "Suporte" revelou o discurso:

"Alimentacão escolar é um suporte que o aluno recebe durante esse período da escola para conseguir desenvolver as suas atividades. $\dot{E}$ a parte educacional mesmo, um suporte, uma alimentação, é um poder muito grande que a gente tem nas mãos para melhorar saúde, aprendizado, acompanbamento e desempenbo na escola. É algo muito importante, tem que suprir as necessidades das crianças, independente da faixa etária, é um tema muito grande em termos de nutrientes, é fundamental para o desenvolvimento das criancas".
Este discurso se identifica com o artigo 2o da Lei Federal no 11.947/2009, em relação a algumas diretrizes do programa de alimentação escolar. Como o emprego da alimentação saudável e adequada, contribuindo para o crescimento e o desenvolvimento dos alunos e para a melhoria do rendimento escolar, em conformidade com a sua faixa etária e seu estado de saúde, inclusive dos que necessitam de atenção específica ${ }^{[3]}$. Desta forma, os nutricionistas demonstram uma visão mais atual e técnica da alimentação escolar.

Por outro lado, apenas dois nutricionistas corresponderam ao discurso que revelou a ideia central "Educação nutricional" cuja inclusão no currículo escolar foi um dos grandes avanços da legislação atual na perspectiva da segurança alimentar e nutricional:

"Alimentação escolar...engloba toda a
questão não só alimentar, mas a educação
nutricional...introdurir bons bábitos
alimentares, envolve toda esta questão social
$e$ educativa também da alimentação, é
elaborar o cardápio de uma forma bem
diversificada, inserindo alimentos que eles
não conbecem... Esse momento também pode
ser utilizado como uma forma de educação
nutricional tanto para ele, como para a
escola como um todo, diretores, professores, o
entorno".

O artigo 2o, inciso II da Lei Federal no 11.947/2009, ainda como diretriz da alimentação escolar, institui "a inclusão da educação alimentar e nutricional no processo de ensino e aprendizagem, que perpassa pelo currículo escolar, abordando o tema alimentação e nutrição e o desenvolvimento de práticas saudáveis de vida, na perspectiva da segurança alimentar e nutricional". Vale ressaltar que este percentual corresponde a apenas dois nutricionistas que entendem alimentação escolar como uma possibilidade de educação alimentar ${ }^{[3]}$.

Nota-se que "Assistencialismo" é uma ideia central comum nos discursos dos gestores. Há também uma percepção semelhante em relação ao significado de "Alimentação escolar", como adequada e saudável. É importante diferenciar assistencialismo, como técnica voluntária e espontânea de doação que ajuda ou favorece as populações carentes, estabelece uma vinculação dos assistidos aos que realizaram a benfeitoria sob o sentimento de gratidão e tutela, de 
assistência que se posiciona como um direito do cidadão, uma política pública[33].

Assim, historicamente se constrói um processo de simbiose no qual os usuários dos serviços públicos não são atendidos na perspectiva do direito, mas, ao contrário, o acesso a bens e serviços assistenciais sempre se dá como resultado da bondade de alguém[ ${ }^{[3]}$.

\section{Entendimento dos gestores sobre a legislação de referência do PNAE}

Para analisar o entendimento sobre a legislação específica do PNAE entre os secretários, foi questionado: "Como o(a) $\mathrm{Sr}(\mathrm{a})$ entende a Lei Federal no 11.947/2009 e a Resolução/CD/FNDE no 26/2013, para colocar o programa municipal de alimentação escolar em funcionamento?" verificaramse ideias centrais, como "Diretriz":

"O PNAE é um programa do governo federal que vem nortear um pouco a elaboração e a oferta de merenda nas escolas. E então, nós temos aí a proposta nutricional nas leis, e algumas regras para a distribuição da merenda. É uma questão de diretriz, um norte, um encaminhamento para a alimentação escolar no município, acho que essas duas legislações nos respaldam e orientam toda producaao, todo controle da qualidade, então ela é a base. Acredito que ela seja importante para delimitar critérios mesmo a niveis nacionais".

As diretrizes do PNAE de acordo com o artigo 2o da Lei Federal, corroboradas pelo artigo 2o da Resolução/CD/FNDE no 26/2013, são o emprego da alimentação saudável e adequada, a inclusão da educação alimentar e nutricional no processo de ensino e aprendizagem, a universalidade do atendimento aos alunos matriculados na rede pública de educação básica, a participação da comunidade no controle social, o apoio ao desenvolvimento sustentável, o direito à alimentação escolar, visando a garantir segurança alimentar e nutricional dos alunos, o que de certa forma se assemelha ao que os secretários entendem sobre a legislação, porém, não se referem ao PNAE como política pública ${ }^{[3,5]}$.

Porém o discurso dos secretários, também traz na mesma proporção a ideia central "Desconhecimento":
"Você está falando do recurso que vem do PNAE? Essas duas legislações pra mim são novas, não estou atualizado em cima delas, não peguei ela, não li a resolução $e$ nem destrinchei o que cada uma delas dir. Não sou um estudioso dessas leis, não conheço, eu sei que tem uma resolução e que a gente procura seguir fielmente".

Estudo realizado por Carvalho ${ }^{[28]}$ entre professores de escola de ensino fundamental II no Distrito Federal, concluiu que $80 \%$ dos gestores desconhecem o funcionamento e a gestão do PNAE. Peixinho et al. [35] ressaltaram em seu estudo que foram realizados entre 2003 a 2010 vários encontros regionais e nacionais de alimentação escolar tendo sido diagnosticada a necessidade de formação de gestores. As capacitações não pretendiam conferir o perfil técnico e/ou administrativo do gestor, mas sim fornecer informações e conhecimentos que subsidiassem suas ações.

A constatação da divergência entre as ideias centrais "Diretriz" e "Desconhecimento" no discurso dos secretários traz uma inquietação, pois eles são os responsáveis na entidade executora pela implementação de uma política pública de visibilidade para o município, que contempla um financiamento externo relevante, que muitos deles dizem que é muito importante para o cotidiano da escola. Mesmo assim, possivelmente, desconhecem a formalização do programa por meio da legislação.

Alguns secretários entendem a legislação como "Regra burocrática":

\footnotetext{
"...uma lei que torna obrigatório, como aquilo que você tem que cumprir, eu preciso oferecer essa alimentação e que seja uma alimentação de qualidade. Resolucōes, a maioria são administrativas e de convênio. O que acontece, tem uma legislação e tem que cumprir a legislação, só que muitas vezes as dificuldades que encontra para cumprir essas leis é enorme porque o papel aceita tudo...".
}

Talvez o não entendimento do significado da alimentação escolar como uma atividade complementar à educação e direito do aluno e ainda, a não apropriação da legislação por parte do secretário, resulte no discurso de que a legislação é apenas uma regra burocrática e não um conjunto de normas para implementar uma política pública. 
É necessário reiterar que a legislação regula as relações sociais, representa muito mais que um conjunto de ordens a serem cumpridas. É a superação do poder do mais forte, do mais rico ou qualquer outro fator de distinção entre os indivíduos, estabelecendo a igualdade entre as pessoas na definição ou garantia dos direitos ${ }^{[36]}$.

Quando os secretários se referem à lei como "ter que cumprir" demonstram falta de aproximação com a gestão pública, uma vez que todos têm formação na área de educação, especificamente. Paula[37] relatou em seus estudos que a Administração Pública tem uma lógica própria, requerendo o desenvolvimento de técnicas de gestão adequadas, além de uma formação específica para os gestores públicos.

Alguns secretários falaram da "Dificuldade" imposta pela legislação:

"Não posso dizer se ela é muito facilitadora
do nosso trabalho. Não é muito
esclarecedora, tem muitos problemas que a
gente tem que fazer uma gestão a parte para
poder dar conta de atender tudo. A gente vêe
que existem alguns dificultadores dessas leis,
algumas coisas que não deixa que ela seja
totalmente viável. A legislação é boa, mas os
mecanismos para executá-las não são bons".

Os municípios relataram diversas situações que dificultam, de fato, a implementação do programa de alimentação escolar, como a não existência de recursos humanos capacitados, a lentidão nas compras públicas, instalações inadequadas para as cozinhas escolares, entre outras.

As dificuldades na gestão do programa no nível municipal têm sido relatadas há algum tempo como no estudo de Nogueira[ ${ }^{[2]}$ baseado na avaliação do MEC/INEP de 1998[38]. É absolutamente comum verificar a dificuldade de gestão em questões logísticas, técnicas e também da inserção do programa no projeto pedagógico da escola pela entidade executora. No nível administrativo, o programa enfrenta inúmeras dificuldades e resistências. As secretarias municipais de educação, geralmente como entidades executoras, deveriam exercer algumas funções básicas no planejamento e execução, porém contaram sempre com número reduzido de funcionários designados à gestão e ao acompanhamento do programa.
Os problemas referentes à insuficiência de infraestrutura para o provimento das instalações, equipamentos e do pessoal para o preparo e distribuição das refeições, foi uma das situações relatada no estudo de Santos et al.[39], como dificultadores da operacionalização dos programas de alimentação escolar no nível local.

Silva e Danelon[40], quando analisaram as informações contidas nos pareceres elaborados no ano de 2003 pelos CAE de 568 municípios das várias regiões geográficas do Brasil, verificaram que a insuficiência dos recursos federais destinados ao programa foi a principal crítica realizada pelos conselheiros. Quanto à infraestrutura do programa as críticas identificadas foram em relação à ausência de estrutura física para a aquisição de gêneros nos municípios, principalmente em relação ao acondicionamento dos perecíveis que demandam a utilização de freezers. Houve também críticas em relação à logística de transporte para a entrega de alimentos às escolas e em relação à falta de nutricionista no programa.

Com relação ao entendimento sobre a legislação pelos nutricionistas foram constatadas ideais centrais, como "Obrigatoriedade":

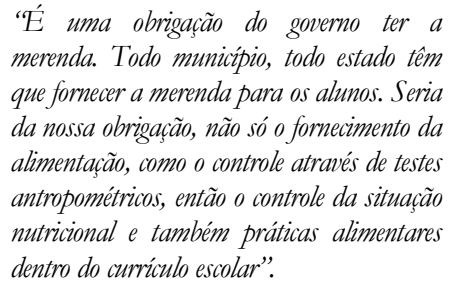
merenda. Todo município, todo estado têm que fornecer a merenda para os alunos. Seria da nossa obrigação, não só o fornecimento da alimentação, como o controle através de testes antropométricos, então o controle da situação nutricional e também práticas alimentares dentro do currículo escolar".

Neste discurso os nutricionistas demonstram a responsabilidade técnica quando se referem a outras atribuições que transcendem ao mero fornecimento da alimentação.

Scarparo et al.[25] concluíram por meio de estudo sobre a efetividade das formações de nutricionistas realizadas pelo Centro Colaborador em Alimentação e Nutrição do Escolar da Universidade Federal do Rio Grande do Sul (CECANE UFRGS), entre 2007 e 2009, quando 95\% dos nutricionistas demonstraram clareza sobre as atribuições, apesar de relatarem a dificuldade em adaptar a teoria à realidade em que atuam. 
O tempo verbal utilizado no discurso dos nutricionistas, numa situação condicional ("Seria de nossa obrigação...”), sugere análise à luz do estudo sobre a atuação do nutricionista no PNAE com ênfase no número de profissionais, nas atribuições, nos avanços e desafios, de Chaves et al. ${ }^{32]}$, onde foram relatadas as dificuldades no atendimento às atividades obrigatórias do nutricionista no âmbito do programa de alimentação escolar, conforme a Resolução CFN no 465/2010[24].

Os dados apresentados demonstraram que houve evolução no percentual de municípios brasileiros com nutricionistas cadastrados no FNDE/PNAE, porém à atividade de elaboração do cardápio foram incorporadas outras atividades técnicas, ampliando a complexidade de suas ações. E neste contexto o não cumprimento de todas as atribuições previstas para o nutricionista certamente está relacionado ao quantitativo de profissionais atuantes no programa, havendo sobrecarga de trabalho quando não há o atendimento do parâmetro numérico mínimo estabelecido na Resolução CFN no 465/2010[24].

Embora os nutricionistas se sintam obrigados a colocar em prática a legislação, também a entendem como um respaldo, uma "Diretriz", assim como os secretários, sendo essa ideia central manifestada por $28 \%$ desses entrevistados:

\footnotetext{
"A lei nos ajuda através desses parâmetros para definir o programa, as metas, os cardápios, tentar seguir da melhor forma possivel o que ela coloca pra gente. Acho fundamental ter uma diretria, ela rege as nossas ações e muito disso está influenciado o lado financeiro, de acordo com essa legislação o que a gente recebe recursos do governo federal. Elas são gerais, eu entendo que elas são necessárias e importantes pra gente padronizar uma questão a nivel nacional..."
}

A partir de 2003 o PNAE passa a ter destaque como um dos programas de governo que visa à formação de hábitos alimentares saudáveis e à segurança alimentar e nutricional dos escolares. Nesse período a coordenação do programa passa a ter, pela primeira vez, um nutricionista como principal gestor, em nível central.

A presença deste profissional à frente do programa, com a inserção de outros nutricionistas à equipe técnica, trouxe contribuições significativas ${ }^{[32]}$, porém é recente a exigência por lei de um profissional na equipe de gestão do PNAE, e necessita, de fato, de diretrizes para poder operacionalizá-lo adequadamente.

Bandeira et al. ${ }^{[11]}$ referiram que entre as atividades realizadas pelo nutricionista, informadas nos pareceres conclusivos dos Conselhos de Alimentação Escolar do Brasil sobre a execução do PNAE, destacase o acompanhamento da aquisição, preparação e distribuição da alimentação escolar seguida de educação nutricional e da coordenação do diagnóstico nutricional.

Os nutricionistas entendem a legislação como diretriz, respaldo, porém as leis não são uma ajuda, uma contribuição, elas precisam ser implementadas e avaliadas, para, se necessário, propor novas formulações.

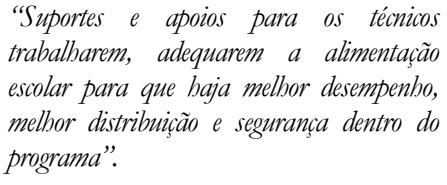

Grande parte dos nutricionistas entende que a legislação é de "Difícil implementação":

\footnotetext{
"É bem complicado conseguir aplicar a lei. A gente não consegue às vezes se enquadrar $100 \%$ na lei. Encontro dificuldades com as questões específicas do município; elas são muito generalizadas, não atendem às particularidades de cada região, são muito amplas. Porém não tem como fazer uma lei para cada município".
}

Em relação ao atendimento às especificidades dos municípios, a legislação permite por meio da aquisição de alimentos da agricultura familiar, que o cardápio seja adequado aos hábitos alimentares locais. Conforme o artigo 14 da Resolução/CD/FNDE no 26/2013, os cardápios devem ser elaborados com utilização de gêneros alimentícios básicos, de modo a respeitar as referências nutricionais, os hábitos alimentares, a cultura da localidade e pautar-se na sustentabilidade, sazonalidade e diversificação agrícola da região e na alimentação saudável e adequada, o que 
pode demonstrar, mais uma vez, que os nutricionistas têm dificuldades de interpretação dessa legislação[ ${ }^{[]}$.

Baeza ${ }^{[42]}$ destacou em seu estudo que entre as vantagens de regionalização do processo de aquisição dos alimentos produzidos localmente, características como a aparência do produto, frescor e identificação do produtor/fornecedor resultaram em maior aceitabilidade dos mesmos por parte dos escolares, reduzindo o desperdício e racionalizando os processos.

Porém, outro fator relevante que pode justificar o discurso dos nutricionistas em relação à dificuldade de implementação é a falta de formação adequada para a atuação no PNAE durante o curso de graduação, segundo estudo de Santos et al.[43].

Este estudo demonstra que apenas as ideias centrais "Diretriz" e "Dificuldade" se apresentam com frequências semelhantes no discurso dos gestores sobre como entendem a legislação do PNAE. Vale ressaltar que existem contradições importantes entre os discursos dos atores. Os secretários entendem a legislação como "Diretriz" e "Desconhecimento", com a mesma frequência (24\%). Enquanto que os nutricionistas entendem a legislação como "Diretriz" e "Obrigatoriedade", também na mesma frequência $(28 \%)$.

\section{CONCLUSÃO}

Este estudo revelou como os gestores públicos da RMC entendem a Lei Federal no 11.947/2009 e a Resolução/CD/FNDE no 26/2013, que definem a implementação do PNAE.

O método do DSC possibilitou conhecer as representações sociais da alimentação escolar entre os gestores da RMC e, de forma geral, os achados corroboram os de outros estudos realizados no Brasil, verificando-se consistência do modus operandi local com a de gestores de outras regiões do País.

As representações sociais de alimentação entre os gestores demonstram que o assistencialismo ainda é fortemente presente. Percebe-se que a política é abstrata no entendimento dos gestores, uma "Ideia" ou uma "Obrigação" de fornecer a "merenda escolar", tida em geral como "alimentação saudável", mesmo um "lanche" que assista principalmente os alunos "que têm só essa refeição". De fato, "merenda" é a representação social de alimentação escolar fortemente revelada, apesar de ser reconhecida por alguns gestores com um conceito ultrapassado.

Os secretários e nutricionistas não se referiram ao PNAE claramente como uma política pública, e sim, à situação concreta da alimentação servida aos alunos no ambiente da escola como assistência. $\mathrm{O}$ entendimento da legislação pelos gestores foi ambíguo: ao mesmo tempo em que direciona, é muito difícil implementá-la. É importante ressaltar que por várias vezes nos discursos, são reveladas situações de desconhecimento da legislação por ambos os gestores, o que dificultaria sobremaneira supervisionar e seguir a lei.

Os discursos dos secretários de educação revelam basicamente seu papel político, como burocratas nem sempre bem preparados para exercer sua função, o que se demonstra principalmente pelo desconhecimento sobre a dimensão do programa de alimentação do município (número e tipo de escolas, número de alunos atendidos, tipo de gestão, etc.), além da superficialidade do entendimento da legislação de referência do PNAE.

Embora o PNAE seja um programa moderno e que garante o direito do aluno à alimentação durante sua permanência na escola, inclusive como parte das atividades pedagógicas, esta pesquisa constatou que a interpretação do programa ainda é assistencialista, enraizada nas políticas compensatórias e não de direito do aluno que frequenta a escola pública. Neste sentido, tanto - e principalmente - os secretários como os nutricionistas consideram a alimentação escolar como a comida fornecida ao aluno carente, um atrativo a sua permanência na escola. Assim, desvirtua-se o caráter pedagógico do PNAE e, de fato, não foram registradas atividades de educação alimentar e nutricional nos discursos dos entrevistados.

Finalizando, ressalta-se a necessidade de capacitação dos gestores, tanto secretários como nutricionistas que atuam no nível municipal, assim como a inclusão de disciplinas voltadas à gestão de políticas públicas não apenas no currículo dos cursos de nutrição, mas também em outros cursos relacionados à educação. Pretende-se que a devolutiva 
dos resultados desta pesquisa para a Câmara Técnica de Educação da RMC, que congrega os secretários de educação dos municípios associados, seja um marco de avaliação e dele se avance na melhoria contínua da gestão da alimentação escolar como direito do aluno e instrumento de educação.

\section{REFERÊNCIAS}

[1] Organização das Nações Unidas - ONU. Com 47 milhões de crianças alcançadas, Brasil é referência global em refeições escolares, [internet]. 2013 [Acesso em 20 ago 2013]. Disponível em: http://www.onu.org.br/com-47-milhoes-de-criancas-alcancadasbrasil-e-referencia-global-em-refeicoes-escolares.

[2] Nogueira RM. O programa nacional de alimentação escolar como uma política pública: o caso de Campinas-SP [dissertação]. Campinas: Universidade Estadual de Campinas; 2005.

[3] Brasil. Ministério da Educação. Lei no 11.947, de 16 de junho de 2009. Dispõe sobre o atendimento da alimentação escolar e do Programa Dinheiro Direto na Escola aos alunos da educação básica. Brasilia: Diário Oficial da União. 17 jun 2009.

[4] Villar BS, Schwartzman F, Januario BL, Ramos JF. Situação dos municípios do estado de São Paulo com relação à compra direta de produtos da agricultura familiar para o Programa Nacional de Alimentação Escolar (PNAE). Revista Brasileira de Epidemiologia. 2013;16:223-226.

[5] Brasil. Ministério da Educação. Resolução no 26, de 17 de junho de 2013. Dispõe sobre o atendimento da alimentação escolar aos alunos da educação básica no âmbito do Programa Nacional de Alimentação Escolar - PNAE. Brasília: Diário Oficial da União. 18 jun 2013.

[6] Brasil. FNDE - Fundo Nacional de Desenvolvimento da Educação. Alimentação Escolar [internet]. 2016 [Acesso em $26 \mathrm{fev}$ 2016]. Disponível em: http://www.fnde.gov.br

[7] Brasil. Ministério da Educação. Resolução no 01 , de 08 de fevereiro de 2017. Altera o valor per capita para oferta da alimentação escolar do Programa de Alimentação Escolar - PNAE. Brasilia: Diário Oficial da União. 09 fev 2017.

[8] World Food Programme - WFP. State of School Feeding Worldwide [internet]. 2013 [Acesso em 18 out 2014]. Disponível em: https://www.wfp.org/content/state-school-feedingworldwide-2013.

[9] Flick U. Uma introdução à pesquisa qualitativa. Porto Alegre: Bookman; 2004.

[10] Lefèvre F, Lefèvre AMC. Pesquisa de Representação Social: um enfoque qualiquantitativo à metodologia do Discurso do Sujeito Coletivo. Série Pesquisa. Brasília: Liber Livro Editora; 2012.
[11] Lefèvre F, Lefèvre AMC. Discourse of the collective subject: social representations and communication interventions. Texto Contexto Enfermagem. 2014;23:502-507.

[12] Moscovici S. Notes towards a description of Social Representations. European Journal of Social Psychology. 1988;18:211-250.

[13] Lefèvre AMC, Crestana MF, Cornetta VK. A utilização da metodologia do discurso do sujeito coletivo na avaliação qualitativa dos cursos de especialização "Capacitação e Desenvolvimento de Recursos Humanos em Saúde CADRHU”, São Paulo - 2002. Saúde e Sociedade. 2003;12: 68-75.

[14] Lefèvre F. O Discurso do Sujeito Coletivo: um novo enfoque em pesquisa qualitativa. Rio de Janeiro: EDUCS. 2006.

[15] Duarte SJH, Mamede MV, Andrade SM. O. Opções teórico metodológicas em pesquisas qualitativas: representações sociais e discurso do sujeito coletivo. Saúde e Sociedade. 2009;18:620-626.

[16] Brasil. Lei Complementar Estadual no 870, 19 de junho de 2000. Cria a Região Metropolitana de Campinas, o Conselho de Desenvolvimento da Região Metropolitana de Campinas e autoriza o Poder Executivo a instituir entidade autárquica, a constituir o Fundo de Desenvolvimento Metropolitano da Região de Campinas, e dá providências correlatas. Brasília: Diário Oficial da União. 20 jun 2000.

[17] Observatório Metropolitano Indicadores da RMC OMI/AGEMCAMP. Conheça a RMC [internet]. 2016 [Acesso em 18 jan 2016]. Disponível em: http://www.agemcamp.sp.gov.br

[18] São Paulo. Lei Estadual no 1.234, 13 de março de 2014. Integra da Região Metropolitana de Campinas o Município de Morungaba. São Paulo: Diário Oficial Estadual. 8 jan 2014.

[19] Programa das Nações Unidas para o Desenvolvimento PNUD. Altas do Desenvolvimento Humano no Brasil [internet]. 2013 [Acesso em 23 jan 2016]. Disponível em: http://www.atlasbrasil.org.br/2013/pt/perfil_rm/campinas

[20] Fundo Nacional de Desenvolvimento da Educação - FNDE. Alunado por ação do Programa Nacional de Alimentação Escolar [internet]. 2016 [Acesso em 24 jan 2016]. Disponível em: http://www.fnde.gov.br

[21] Lawless HT, Heymann H. Sensory Evaluation of Food Principals and Practices. Gaithersburg: Aspen Publishers, 2010.

[22] Perezini BO et al. A hierarquia da atitude do consumidor segundo a relevância de seus componentes: um estudo sobre os modelos teóricos e sua aplicabilidade na economia verde. Business and Management Review. 2015;4:230-240.

[23] Instituto de Pesquisa do Discurso do Sujeito Coletivo IPDSC. Qualiquantisoft [internet]. 2011 [Acesso em 20 mar 2013]. Disponível em: http:/ /www.ipdsc.com.br/scp/qualiquantisoft.php 
[24] Brasil. Ministério da Educação. Resolução no 465, de 23 de agosto de 2010. Dispõe sobre as atribuições do nutricionista, estabelece parâmetros numéricos mínimos de referência no âmbito do Programa de Alimentação Escolar (PAE) e dá outras providências. Brasilia: Diário Oficial da União. 23 ago 2010.

[25] Scarparo ALS et al. Formação para nutricionistas que atuam no programa nacional de alimentação escolar: uma avaliação da efetividade. Ciência \& Saúde Coletiva. 2013;18:1001-1008.

[26] Camozzi ABQ, Monego ET, Menezes IHCF, Silva PO. Promoção da alimentação saudável na escola: realidade ou utopia? Caderno Saúde Coletiva. 2015; 23:32-37.

[27] Freitas MCS et al. Escola: lugar de estudar e de comer. Ciência \& Saúde Coletiva. 2013;18:979-985.

[28] Carvalho DGO. Programa Nacional de Alimentação Escolar e a sustentabilidade: o caso do Distrito Federal (2005-2008) [dissertação]. Brasilia: Universidade de Brasília; 2009.

[29] Bezerra JAB. Alimentação e escola: significados e implicações curriculares da merenda escolar. Revista Brasileira de Educação. 2009;14:103-115.

[30] Brasil. Ministério da Educação. Resolução no 07, de 08 de março de 2000. Estabelece a transferência dos recursos financeiros automaticamente, sem mais a necessidade de firmar convênio, à entidade executora. Brasília: Diário Oficial da União, 10 mar 2000.

[31] Rodrigues J. Alimentação popular em São Paulo (1920 - 1950) - políticas públicas, discursos técnicos e práticas profissionais. Anais do Museu Paulista. 2007;15: 221-255.

[32] Chaves LG, Santana TCM, Gabriel CG, Vasconcelos FAG. Reflexões sobre a atuação do nutricionista no Programa Nacional de Alimentação Escolar no Brasil. Ciência e Saúde Coletiva. 2013;18:917-926.

[33] Junior J. Fundamentos históricos, teóricos e metodológicos do serviço social, Universidade Paulista [internet]. 2011 [Acesso em 04 abr 2016]. Disponível em: http://unipvirtual.com.br

[34] Silva FC. Assistência social e cultura política: o processo de uma política em construção [dissertação]. Juiz de Fora: Universidade Federal de Juiz de Fora; 2012.

[35] Peixinho A, Balaban D, Rimkus L, Schwartzman F, Galante AP. Alimentação escolar no Brasil e nos Estados Unidos. O Mundo da Saúde. 2011;35:128-136.

[36] Pacheco RG, Cerqueira AS. Legislação Educacional. Brasília: Universidade de Brasília; 2009.

[37] Paula APP. Administração pública brasileira entre o gerencialismo e a gestão social. Revista de Administração de Empresas. 2005;45:36-39.
[38] Draibe SM. Descentralização das políticas sociais: o que ensinam as experiências recentes da merenda escolar, do dinheiro na escola e da TV Escola, Caderno de Pesquisa. 1998;36.

[39] Santos LMP et al. Avaliação de políticas públicas de segurança alimentar e combate à fome no período 1995-2002 - Programa Nacional de Alimentação Escolar. Caderno de Saúde Pública. 2007;23:2681-2693.

[40] Silva MV, Danelon MS. Conselhos de Alimentação Escolar (CAEs): análise dos pareceres conclusivos sobre a execução do Programa Nacional de Alimentação Escolar (PNAE). Segur. Aliment. Nutr. 2013;20:122-135.

[41] Bandeira LM, Chagas CMS, Gubert MB, Toral N, Monteiro RA. Análise dos pareceres conclusivos dos Conselhos de Alimentação Escolar sobre a execução do Programa Nacional de Alimentação Escolar. Rev. Nutr. 2013;26:343-351.

[42] Baeza VF. Impacto da merenda regionalizada no desempenho escolar em alunos de duas escolas da rede municipal de Manaus/AM [dissertação]. Manaus: Universidade Federal do Amazonas; 2014.

[43] Santos LAS, Paiva JB, Mello AL, Fontes GAV, Sampaio LR, Freitas MCS. O nutricionista no programa de alimentação escolar: avaliação de uma experiência de formação a partir de grupos focais. Rev. Nutr. 2012;25:107-117. 